\title{
Age Is Not a Limiting Factor in Interventional Radiotherapy (Brachytherapy) for Patients with Localized Cancer
}

\author{
Valentina Lancellotta $\mathbb{D}^{1},{ }^{1}$ György Kovács, ${ }^{2}$ Luca Tagliaferri, ${ }^{3}$ Elisabetta Perrucci, ${ }^{4}$ \\ Giuseppe Colloca, ${ }^{5}$ Vincenzo Valentini, ${ }^{6}$ and Cynthia Aristei ${ }^{1}$ \\ ${ }^{1}$ Radiation Oncology Section, Department of Surgery and Biomedical Sciences, University of Perugia and Perugia General Hospital, \\ Perugia, Italy \\ ${ }^{2}$ Interdisciplinary Brachytherapy Unit, University of Lübeck/UKSH-CL, Lübeck, Germany \\ ${ }^{3}$ Polo Scienze Oncologiche ed Ematologiche, Università Cattolica del Sacro Cuore, \\ Fondazione Policlinico Universitario Agostino Gemelli, Roma, Italy \\ ${ }^{4}$ Radiation Oncology Section, Perugia General Hospital, Perugia, Italy \\ ${ }^{5}$ Polo Scienze Oncologiche ed Ematologiche, Università Cattolica del Sacro Cuore, \\ Fondazione Policlinico Universitario Agostino Gemelli, Gruppo Italiano di Oncologia Geriatrica (GIOGER), Roma, Italy \\ ${ }^{6}$ Polo Scienze Oncologiche ed Ematologiche. Istituto di Radiologia, Università Cattolica del Sacro Cuore, \\ Fondazione Policlinico Universitario Agostino Gemelli, Roma, Italy \\ Correspondence should be addressed to Valentina Lancellotta; valentina.lancellotta@unipg.it
}

Received 18 August 2017; Revised 4 December 2017; Accepted 25 December 2017; Published 21 January 2018

Academic Editor: Pierfrancesco Franco

Copyright (C) 2018 Valentina Lancellotta et al. This is an open access article distributed under the Creative Commons Attribution License, which permits unrestricted use, distribution, and reproduction in any medium, provided the original work is properly cited.

\begin{abstract}
This review examines the role of interventional radiotherapy (IRT otherwise known as brachytherapy) in cancer treatment for elderly patients. Despite their advanced age and associated comorbidities, elderly patients should receive definitive cancer therapies, including surgery and radiotherapy (RT). In fact, RT becomes first-line option for patients who are not eligible for surgery (due to comorbidities, anticoagulant drugs, and risk of disfigurement) or those who refuse it. It emerged from this review of the literature as effective, simple, safe, and comfortable and was associated with good local control, low toxicity rates, and excellent cosmesis and provided a cost benefit. IRT may be used as sole treatment for small cancers or as a useful adjunct to surgery or external beam radiotherapy (EBRT) in more advanced (or lymph node positive) cases, especially when the aim is local control with adequate preservation of normal tissue function. As palliative treatment, IRT preserves quality of life and/or improves survival. It is to be hoped that this review will serve as a helpful guide for members of multidisciplinary teams that are involved in treating elderly patients with cancer.
\end{abstract}

\section{Introduction}

The National Institute on Aging described aging in our society as a "silver tsunami for which we are unprepared." Being a complex multidimensional, dynamic process deriving from interactions among a range of environmental and genetic factors, aging leads to loss of functional reserve and organ system susceptibility to gradual deterioration, that is, "frailty" [1-3]. Since over $50 \%$ of tumors are currently diagnosed in patients aged 65 years or more and the rate is expected to rise to $70 \%$ by 2030 , the management of elderly cancer patients is a major issue for health authorities. This is particularly worth noting since they constitute a heterogeneous group due to differences in lesion locations, multimorbidities, physical or functional performance status, social support, and physiological age-related changes, which may make surgery, which is often the first-line option for many cancers, not feasible in this advanced age group [4].

When assessing the elderly and adapting treatment to them, clinicians should focus on identifying frail or prefrail patients as age-related status determines their ability to tolerate and comply with treatment, their survival, and 
TABLE 1: Comparison of different radiotherapy techniques regarding local dose application potentials.

\begin{tabular}{lcccc}
\hline & CK & IMRT & IGRT & IRT \\
\hline Target definition & Worse & Worse & Worse $^{*}$ & Better \\
Interfraction movements & Better & Worse & Better & Better \\
Intrafraction movements & Better & Better (4D) & Better \\
Target dose painting & Better & Better (4D) $(4 \mathrm{D})$ & Worse \\
Low dose volumes & Worse & Worse & Worse & Better \\
OAR's dose & Better & Worse & Better & Better \\
Invasivity & Better & Better & $>2 \mathrm{~cm}^{3}$ & Worse \\
Smallest reasonable CTV & $0.5 \mathrm{~cm}^{3}$ & $>2 \mathrm{~cm}^{3}$ & $0.5 \mathrm{~cm}^{3}$ \\
\hline
\end{tabular}

CK = cyberknife; IMRT = Intensity Modulated Radiotherapy; IGRT = Image Guided Radiotherapy; IRT = interventional radiotherapy (brachytherapy); CTV $=$ Clinical Target Volume; Worse ${ }^{*}=$ turns into "better" if image fusion is used for treatment planning; $4 \mathrm{D}=$ four-dimensional external beam radiotherapy.

quality of life $[5,6]$. These factors may also be associated with delayed diagnosis and in fact a significant relationship emerged between age and disease stage at diagnosis in different tumor sites [7]. On the other hand, the biological aggressiveness of tumors in aged patients also seems to vary with the individual's age, being lower for some histological types in older patients [8-10]. Indeed, some clinical studies concluded that, for selected patients, the age factor does not decrease tolerance to more aggressive treatments [11-13].

Even though RT indications in elderly cancer patients have long been debated, at present age alone no longer constitutes a counter-indication and if the aim of radiotherapy is curative, there is no age-related indication for a dose reduction [14, 15]. The modern consensus is that elderly cancer patients should receive RT, if their performance status is adequate and the extent and severity of comorbidities do not preclude it.

Consequently, RT is often treatment of choice for the aged, and IRT, which was less likely to be delivered for patients $\geq 80$ years, may be considered competitive, when compared with other radiotherapy modalities or cancer treatments [16]. The American Brachytherapy Society (ABS) recently published a consensus statement that provides detailed technical guidance for IRT for medically inoperable cancer [2], with emphasis on IRT with or without EBRT for most patients. The Radiotherapy Task Force of the International Society for Geriatric Oncology (SIOG) provided recommendations for RT in elderly patients without focusing on IRT, which offers several advantages over external beam techniques [17]. Even though IRT delivery often requires anesthesia, particularly in perioperative or interstitial settings, treatment times are shorter, less normal tissue is irradiated, and gating techniques are not needed to counteract patient movement. Local dose applications using different radiotherapy techniques are compared in Table 1 . The following review focuses on IRT applications in this growing cohort of elderly patients and summarizes the evidence for offering it to them, considering that IRT was associated with acceptable toxicity rates in the elderly and that some types of acute side effects are observed more frequently in younger patients [18].

\section{Material and Methods}

On 12 April and 17 July 2017, MEDLINE searches with "brachytherapy" and "elderly" as key words were performed in the Knowledge Finder ${ }^{\circledR}$ and Scopus ${ }^{\circledR}$ databases for the years 2012-2017. Knowledge Finder yielded 24 publications, 13 of which were relevant. Scopus provided 387 reports, 26 of which were relevant. Pertinent reports encompassed the following categories: general $(n=3)$, anal and rectum $(n=4)$, bile duct $(n=2)$, uterine cervix $(n=2)$, uterine corpus $(n=1)$, vaginal and vulvar $(n=1)$, head and neck $(n=6)$, esophagus $(n=1)$, lung $(n=1)$, prostate $(n=4)$, skin $(n=2)$, and breast $(n=2)$ respectively. All reports were studied and analyzed.

\section{Results and Discussion}

IRT is used alone or as a boost to external beam RT (depending on tumor site and the patient's condition) $[19,20]$. IRT alone is associated with excellent outcomes as local control, patient survival rates, cosmetic results, and the incidence and severity of side effects did not differ in the aged and in younger populations [21-25]. Although the combination therapy (EBRT + IRT) is associated with the highest overall survival (OS) rate, nearly $40 \%$ of patients do not receive either surgery or radiotherapy and are treated with systemic therapy alone (e.g., endocrine therapy). The incidence of late toxicity ranged from $0 \%$ to $21 \%$. After high dose-rate- (HDR-) IRT alone or in combination with EBRT, Disease Specific Survival (DSS) and low complication rates, with no grade 3 or higher acute toxicities, were similar in patients aged 75-92 years (median 83 years) and other EBRT studies [26].

3.1. Anal and Rectal Cancer. Because of potential complications or poor organ function, patients aged 70 years or more are not usually considered as suitable candidates for surgery or radiochemotherapy. Although they were often treated with palliative RT, they might benefit from a more radical approach using RT alone [27]. Promising results were achieved with contact X-ray RT, which delivers high doses to the tumor surface, in combination with EBRT in inoperable patients [28-31]. An alternative to contact X-ray for inoperable patients is HDR endorectal IRT $[32,33]$ which was 
assessed in association with EBRT in a few retrospective studies [34, 35]. No agreement emerged on the optimal dose, toxicity profile, or treatment schedules. Despite these limitations, all studies reported a response rate of almost $90 \%$, with approximately $60 \%$ complete remission (CR) and a good local progression-free survival rate (L-PFS) in complete responders [28-33, 36]. IRT alone or as a boost to EBRT (+/- chemotherapy) also provided excellent results [37-39]. Furthermore, the toxicity rate was acceptable in all reports and anal function was preserved. The latter parameter is one of the major objectives of anal and rectal cancer therapy because colostomy is a major impairment to quality of life and should always be avoided, if possible.

3.2. Bile Duct Cancer. As extrahepatic biliary carcinoma (EBC) is rare, accounting for about $2-6 \%$ of all cancer [40], few data can be extrapolated as referring specifically to the aging population.

Although endoscopic stenting is first-line palliative therapy, stent occlusions rates of $30-45 \%$ were reported, as palliative treatment EBRT alone prolongs survival and reduces symptoms but only with major local dose escalation which is, unfortunately, limited by the tolerance of critical organs like the liver, kidneys, and small bowel.

Intraluminal IRT (ILIRT), an optimal technique for delivering a high dose to a well-defined small volume and the shortest possible treatment time, has the further advantage of respecting the dose constraints of organs at risk. In a retrospective comparison of 30 patients treated with selfexpanding metallic stent (SEMS) + ILIRT versus SEMS alone, Karani et al. reported the combined approach was associated with longer prolongation of biliary patency and up to 16.8 months longer mean OS [41]. Válek et al. randomized 42 patients to either palliative stent placement or stent placement with ILIRT followed by EBRT, reporting that OS was significantly increased in patients who received ILIRT [42]. OS rates at 6,12 , and 18 months after SEMS + ILIRT in 18 patients with nonmetastatic extrahepatic biliary cancer (median age 79 years, range 61-86) were 77\%, 59\%, and 37\%, respectively. Only one patient developed G3 gastrointestinal toxicity [43].

Consequently, we agree that bile duct ILIRT should be treatment of choice in some cases, depending on lesion location [40] because it plays a limited, but specific role, in curing early disease, has a place in the postoperative treatment of small residual disease, and is useful as palliative therapy.

\subsection{Gynecological Cancer}

3.3.1. Cervix Cancer. Although radiochemotherapy including IRT is standard treatment for locally advanced or inoperable cervical cancer, data are based on studies with the majority of the patients under 70 years $[44,45]$ and few data are available about treatments, toxicities, and outcomes in elderly women. The National Cancer Institute's Surveillance, Epidemiology, and End Results (SEER) database contains data on 28902 patients with cervical cancer but only $13.5 \%$ were $\geq 70$ years old. Elderly women usually suffered from squamous cell tumors, G3, and advanced stage disease [6] and were treated differently from younger patients [46-49]. After surgery for early stage disease, elderly patients were less likely to receive curative or adjuvant radiotherapy, even when there was an indication. For example, $20 \%$ aged $70-79$ years and $40 \%$ aged $>80$ years did not receive IRT [50].

Lin et al. recruited 126 patients with cervical cancer (median age 81.5 years; range 75-98) who underwent curative (81 received definitive RT, 10 adjuvant $\mathrm{RT}$ ) or palliative RT [51]. Overall, 3- and 5-year OS rates were, respectively, 52.7\% (95\% CI, 43-61) and 41.2\% (95\% CI, 32-49), while Recurrence-Free Survival (RFS) rates were 62.88\% (95\% CI 53-70) and 59.51\% (95\% CI, 49-67), respectively. In 91 patients who received curative RT, 3- and 5-year OS rates were, respectively, 66.63\% (95\% CI, 55-75) and 54.48\% (95\% CI, 43-64), while RFS rates were $75.86 \%$ (95\% CI, 65-83) and $71.57 \%$ (95\% CI, 60-80), respectively. G3 gastrointestinal toxicity was observed in $7 \%$ of patients. No G3 bladder and vaginal toxicity was reported.

In underlining the importance of individualized treatment, Chen et al. [52] included IRT in the treatment regimen of elderly patients with cervical cancer. Adapting the IRT schedule to the patient's general condition ensures the shortest possible total treatment time. In comparing outcomes in the 70 and 80 age groups, Yanazume et al. stated that incomplete intracavitary IRT significantly decreased survival rates [53].

3.3.2. Endometrial Cancer. It occurs mainly in elderly women with a median age of 68 years at diagnosis who usually presented with unfavorable prognostic factors like nonendometrial histology, advanced stage, G3, and more aggressive immunological characteristics [54-57]. They have a higher recurrence rate and cancer-specific mortality than younger women and are often undertreated [58-60]. Lymphadenectomy, RT, and systemic treatment are less likely to be administered to older women [57, 61-63]. Lymphadenectomy was not recommended for $58.2 \%$ of patients aged $71-80$ years versus $30.8 \%$ of those aged $\geq 81$ years, respectively. RT was not recommended for $76.6 \%$ versus $51 \%$ of cases and systemic therapy was not recommended for $58.6 \%$ versus $25 \%$ [64]. Elderly patients did not have more perioperative complications than younger patients but it should be borne in mind that laparoscopy was associated with less morbidity than laparotomy in terms of sedation time, blood loss, and perioperative complications [65-68]. After surgery, pelvic/vaginal relapse rates were higher in patients who did not receive adjuvant RT [69].

RT provided good local control and low toxicity and improves OS, particularly when EBRT was combined with IRT [70]. Indeed, 10-year DSS and OS rates were, respectively, $75.1 \%$ and $30.2 \%$, in 228 patients with stage I endometrial cancer who were treated with IRT alone [71]. Furthermore, the American Brachytherapy Society published a consensus statement with emphasis on IRT with or without EBRT for inoperable endometrial cancer. They recommended IRT alone for inoperable, clinical stage I endometrial cancer when there was no MRI evidence of lymph node involvement or deep myometrium invasion [72]. Decision-making, however, needs to balance risk factors and the patient's health status, 
independently of age. In assessing the impact of adjuvant radiotherapy (EBRT $+/-$ IRT) in terms of feasibility and activity in women aged $\geq 75$ years, Fiorica et al. observed survival was significantly better in patients with no, or only mild, comorbidities and concluded that aggressive treatment risked shortening life expectancy in patients with severe comorbidities [73]. Indeed, the right treatment schedule for them could well be conservative surgery combined with postoperative intravaginal IRT.

3.3.3. Vulva and Primary Vagina Cancer. The rare vaginal and vulvar cancer account for only $4 \%$ of gynecological malignancies. Known risk factors are age, smoking, human papilloma virus, or human immunodeficiency virus infection as well as other genital cancers. The average age at diagnosis of invasive vulvar cancer is 70 years and $50 \%$ of vaginal cancers occur in women aged $\geq 70$ years [72]. Since most elderly patients have multiple comorbidities that often restrict treatment options [74], locally advanced or recurrent vulvar cancer may become a serious treatment issue.

IRT as monotherapy or in association with EBRT [75-83] can exert local control in the majority of patients with acceptable morbidity rates. Results with multimodality treatment varied with cancer stage: $86 \%$ of patients with stage I/II vulvar cancer achieved DFS at 5 years, which dropped to $54 \%$ for stage III/IVA and $16 \%$ for stage IVB [84]. In vaginal cancer 5year DFS rates were, respectively, 80-90\%, 35-78\%, 30-59\%, and $0-58 \%$ for stages I, II, III, and IV. After interstitial IRT, patients exhibited milder but similar rates of late mucosal reactions and more severe stenosis than after intracavitary IRT [85].

3.4. Head and Neck Cancer. IRT offers excellent long-term results as local treatment of head and neck $(\mathrm{H} \& \mathrm{~N})$ cancers [86] in "elderly patients" with the cut-off being usually set at age 65 years [87]. Even though advanced age usually precludes elective neck surgery or RT, it should be considered for locally advanced N0 cases. If even node dissection is not performed the relapse risk rises to over 20\% [88].

Performance status is the major factor in treatment tolerance, followed by tumor stage, anatomic site, and oral hygiene status. Even though surgery is first-line treatment of choice if the tumor is resectable, a satisfactory surgical margin may be associated with significant loss of function and/or cosmetic compromises, which could potentially be overcome by combining surgery with perioperative IRT [89]. In fact, in resected $\mathrm{H} \& \mathrm{~N}$ cancer, the complication rates, locoregional failure, and disease-free survival were similar to limitedvolume perioperative HDR-IRT and wide-field EBRT, despite a much smaller treatment volume. Careful delineation of the areas at high risk of recurrence may provide a useful basis for volume reduction and improve the therapeutic ratio [90].

After IRT treatments for primary irradiated oral cavity and oropharynx cancers, Yuasa-Nakagawa et al. reported DSS and OS rates of $63 \%$ and $49 \%$, respectively [91]. No significant differences emerged in 2- and 5-year local control rates of node negative tongue cancer when very elderly ( $\geq 80$ years) patients were compared with younger counterparts $(91 \%$ versus $82 \%)$. The included intercurrent deaths OS rates were
$55 \%$ at 2 years and $34 \%$ at 5 years [92]. On the other hand, 7 years after IRT for tongue cancer Khalilur et al. observed $70 \%$ DSS rates in patients $\geq 80$ years compared with $41 \%$ in the cohort $\leq 80$ [93]. HDR-IRT provided excellent results in a large cohort of patients with lip cancer, as local control rates were $100 \%$ in $\mathrm{T} 1,93.9 \%$ in $\mathrm{T} 2$, and $80 \%$ in $\mathrm{T} 4$ cancers. Unfortunately no information was available on age-related outcomes in this study [94].

Outcomes varied after nasopharyngeal cancer treatment in the elderly compared with the general adult population. Zhang et al. reported that EBRT +/- IRT boost might inherently predict poor outcomes in elderly patients, as the cure rate correlated strongly with the applied dose. Unfortunately, the cohort size precluded comparing different boost methods at the same dose levels [95].

3.5. Esophagus Cancer. Although esophagus cancer occurs in $19.6 \%$ of patients aged $\geq 75$ years $[96,97]$, elderly patients underwent less surgery, radiotherapy, and chemotherapy than younger cohorts. Patient's age, lymph node-status, and radiation dose determine the optimal individualized treatment for the elderly. The RTOG 8501 study showed platinumbased chemotherapy plus EBRT benefited OS more than EBRT alone. EBRT + IRT provided good outcomes in locally advanced esophageal squamous cell cancer [98]. In a retrospective cohort study of 191 patients (median age 75 years, range 70-84), Li et al. reported 1-, 2-, 3-, and 5-year OS rates of $68.5 \%, 48.2 \%, 40.3 \%$, and $28.7 \%$, respectively [99] with 1, 2-, 3-, and 5-year rates for locoregional control of $82.2 \%$, $67 \%, 61.8 \%$, and $54.2 \%$, respectively. EBRT + IRT appeared to be efficacious, with acceptable toxicity levels as there were no perforations, 33.5\% G2 esophagitis, $2.6 \%$ fistula, and $7.9 \%$ massive bleeding. HDR-IRT alone or in combination with EBRT is also excellent for palliation of pain, dysphagia, or obstruction. After randomizing 41 patients to receive SEMS placement followed by HDR-IRT or HDR-IRT alone, Amdal et al. concluded that combination treatment with SEMS and HDR-IRT may be indicated for patients needing immediate dysphagia relief, while HDR-IRT alone may be indicated for less urgent cases as it was associated with a lower rate of complications [100].

3.6. Lung Cancer. IRT may be applied as a curative/palliative monotherapy in elderly patients with lung cancer. ILIRT is optimal for treating intraluminal obstruction due to tumor infiltration which is one of the major symptoms of lung cancer and may be combined with stenting and/or laser resection. It is rarely used intraoperatively after wedge resection with either implantation of plastic tube applicators for HDRIRT or low dose-rate (LDR) isotopes. Response rates of 97\% for hemoptysis, 93\% for dyspnea, 91\% for obstructive pneumonia, and $82 \%$ for cough were reported, respectively [101]. McKenna et al. reported on the combination of wedge resection and interstitial perioperative IRT in 48 patients with poor pulmonary function who underwent wedge resection, node dissection, and HDR-IRT with a dose of 7x $3.5 \mathrm{~Gy}$ in 4 treatment days. After a 13.5-month follow-up, three local recurrences were observed [102]. Santos et al. compared wedge resection versus wedge resection and intraoperative 
I-125 seed implantation in cohorts of 101 and 102 stage I non-small-cell lung cancer (NSCLC) cases. No significant differences emerged in morbidity, mortality, and survival but the implanted group had significantly fewer local recurrences ( $2 \%$ versus $19 \%, p=0.0001)$ [103]. Furthermore, after one cycle of first-line chemotherapy and CT guided I-125 seed implantation in locally advanced NSCLC, Song et al. reported survival and quality of life were significantly better than with best supportive care [104].

Combining EBRT + ILIRT, however, seems to be meaningful only if large, intraluminal tumors remain after completing EBRT. In a meta-analysis of 13 randomized trials, EBRT + ILIRT did not improve symptom control or OS compared with EBRT alone [105]. Similarly, a meta-analysis of 29 trials of endobronchial IRT + EBRT in NSCLC found it to be more effective for symptom relief than EBRT alone [106].

3.7. Prostate Cancer. Because of the rise in the aging population, interest is currently focusing on the increased incidence of prostate cancer. Age is the greatest risk factor since autopsy studies have found prostate cancer in $30 \%$ men $\geq 50$ years [107]. As the elderly undergo fewer check-ups than younger men [108], prostate cancer may already have metastasized at the time of diagnosis.

HDR and LDR IRT play central roles at all stages of prostate cancer treatment. They are used as monotherapy in localized disease, as complementary to EBRT (+/- antiandrogen treatment), or as a salvage treatment for local recurrences [109].

Choice of treatment in localized or locally advanced prostate cancer needs to be based on risk categories [110]. Cooperberg et al. described the danger of overtreatment in the elderly [111]. In 4,4630 men aged 65 to 80 years, Wong et al. reported better survival rates with active treatment rather than watchful waiting for low- and intermediate-risk subgroups [112].

HDR-IRT is established as successful monotherapy in low-, intermediate-, and carefully selected high-risk localized prostate cancer [113-115]. In an investigation into the relationships between therapy and prostate cancer-specific mortality (PCSM) in elderly high-risk patients, Hoffman et al. observed that PCSM was lower in patients without preexisting or surgically corrected cardiovascular disease, particularly if they received antiandrogen therapy combined with IRT and EBRT [116].

Long-term results ( $>10$ years) of IRT are good with no biochemical evidence of disease in $60-98 \%$ of patients, according to their risk category [117]. When local recurrences occur after EBRT or radical prostatectomy failure, IRT salvage treatment can be offered to selected cases as shown by evidence from a pooled-analysis study [118] and Niehoff et al. [119].

3.8. Skin Cancer. The increase in nonmelanoma skin cancer (NMSC) in European populations has become a major public health concern and will presumably impact greatly on healthcare costs $[120,121]$. With basal cell cancer (BCC) accounting for $80-90 \%$ of NMSC, surgery is first-line treatment with RT as a valid alternative, particularly in elderly patients [122].
Although few studies have compared surgery and RT, a recent meta-analysis concluded that both are effective, safe, and associated with low recurrence rates [123]. In several studies HDR-IRT emerged as suitable one for elderly patients because of its short treatment time and low toxicity rates [124], achieving a $100 \%$ complete remission rate in a retrospective study of 20 patients with 23 lesions, with erythema being reported as the most frequent adverse event. Cosmesis was excellent as over $60 \%$ of cases were without skin alterations [124].

In another study, 11 patients, with a median age of 80 years, poor performance status, and scalp and face skin lesions, were treated with customized applicators. After a median follow-up of 16 months the 2-year local control rate was $91 \%$, with no high-grade skin toxicity and only low-grade dermatitis (grade I: 50\%, grade II: 33\%) [125].

3.9. Breast Cancer. Approximately $45 \%$ of breast cancers develop in women aged $>65$ years and $33 \%$ in women aged $>70$ years $[126,127]$. Although these data no studies have focused on elderly women who are often undertreated compared with younger counterparts $[128,129]$, consequently, the cancer mortality reduction cannot be compared [130, 131]. In a randomized clinical study, 636 women (age $>70$ years, clinical stage I, estrogen receptor (ER) positive, and breast carcinoma treated by lumpectomy) were assigned to Tamoxifen plus RT (317 women) or Tamoxifen alone (319 women). Median follow-up was 12.6 years. At 10 years, the disease-free local and regional recurrences were $98 \%$ in Tamoxifen and RT arm compared with $90 \%$ in the Tamoxifen alone group. No significant differences emerged in time to mastectomy or distant metastasis, breast cancer-specific survival, or OS [132].

In another randomized clinical trial, 1326 women, aged 65 years or older with low-risk early breast cancer who had had breast-conserving surgery and were receiving adjuvant endocrine treatment, were assigned to whole-breast RT (40-50 Gy in 15-25 fractions) or no RT. After a median follow-up of 5 years, ipsilateral breast tumor recurrence was $1.3 \%$ in women assigned to whole-breast RT and $4.1 \%$ in those who received none ( $p=0.0002)$. No intergroup differences emerged in regional recurrence, distant metastases, contralateral breast cancers, or new breast cancers. The 5-year OS rate was $93.9 \%$ in both groups $(p=0.34)$ [133].

In 79 elderly low-risk breast cancer patients (median age 77 years; range 66-89), Sumodhee et al. [134] tested accelerated Partial Breast Irradiation (APBI) against wholebreast irradiation (WBI) or endocrine therapy alone. Median follow-up was 96.8 months (range 68.6-104.9). Expected 5- and 10-year mastectomy rates without WBI were $2.95 \%$ and $7.25 \%$, respectively, leading to a 10 -year metastasis-free survival (MFS) rate of 92.7\%. Instead, expected 5- and 10year mastectomy rates following WBI were $1.41 \%$ and $3.66 \%$, respectively. The 10 -year MFS rate after APBI was $97.4 \%$ versus $96.3 \%$ after WBI $(p=1)$ and $92.7 \%$ after no irradiation ( $p=0.27$ ). No grade 3 or grade 4 toxicity was observed.

Genebes et al. evaluated 70 APBI patients (median age 80.7 years; range: $62-93.1$ ) with, respectively, $61.4 \%, 18.6 \%$, and $20 \%$ classified as suitable, cautionary, and unsuitable cases according to American Society for Radiation Oncology (ASTRO) criteria. In interstitial multicatheter HDR-IRT, 
catheters were implanted intra- or postoperatively following lumpectomy and axillary sentinel lymph node dissection. Patients had a median follow-up of 60.9 months (range 4.6-90.1). The 5-year local recurrence-free rate was $97.6 \%$. Five-year specific and overall survival rates were $97.9 \%$ and $93.2 \%$, respectively. Late complications in $48 \%$ of patients encompassed grade $1(80.8 \%)$ and grade $2(19.2 \%)$ with no grade $\geq 3$. Cosmetic results were considered excellent/good in 67 patients $(95.7 \%)$ [135].

\section{Conclusions}

Evidence from this review shows that IRT therapy is of benefit to elderly patients with cancer, whatever its location or stage and whether IRT is used as monotherapy in combination with other agents or as palliative therapy. Treatment decisions in elderly cancer patients need to be taken by a multidisciplinary team, who carefully analyze tumor extent, the therapeutical alternatives, and the patient's preferences. Quality of life is probably a major outcome measure for the elderly as they value its preservation over receiving aggressive treatments with certain toxicity profiles. In terms of the patient's midterm quality of life, IRT is the optimal method for applying very high doses locally with maximal preservation of normal neighboring structures in the shortest total treatment time. Additional research into IRT is, however, needed, to strengthen the evidence for its use in elderly cancer patients $[136,137]$.

\section{Conflicts of Interest}

The authors declare that they have no conflicts of interest.

\section{References}

[1] A. W. Kennedy, J. S. Flagg, and K. D. Webster, "Gynecologic cancer in the very elderly," Gynecologic Oncology, vol. 32, no. 1, pp. 49-54, 1989.

[2] J. K. Schwarz, S. Beriwal, J. Esthappan et al., "Consensus statement for brachytherapy for the treatment of medically inoperable endometrial cancer," Brachytherapy, vol. 14, no. 5, pp. 587599, 2015.

[3] G. Colloca, A. Corsonello, E. Marzetti et al., "Treating cancer in older and oldest old patients," Current Pharmaceutical Design, vol. 21, no. 13, pp. 1699-1705, 2015.

[4] H. Wildiers, P. Heeren, M. Puts et al., "International society of geriatric oncology consensus on geriatric assessment in older patients with cancer," Journal of Clinical Oncology, vol. 32, no. 24, pp. 2595-2603, 2014.

[5] L. Balducci, G. Colloca, M. Cesari, and G. Gambassi, "Assessment and treatment of elderly patients with cancer," Surgical Oncology, vol. 19, no. 3, pp. 117-123, 2010.

[6] L. P. Fried and W. J. Hall, "Editorial: Leading on behalf of an aging society," Journal of the American Geriatrics Society, vol. 56, no. 10, pp. 1791-1795, 2008.

[7] F. F. Holmes and H. Erwin, "Cancer Stage-to-Age Relationship: Implications for Cancer Screening in the Elderly," Journal of the American Geriatrics Society, vol. 29, no. 2, pp. 55-57, 1981.

[8] N. A. Rodrigues, D. Dillon, D. Carter, N. Parisot, and B. G. Haffty, "Differences in the pathologic and molecular features of intraductal breast carcinoma between younger and older women," Cancer, vol. 97, no. 6, pp. 1393-1403, 2003.

[9] S. M. Teeter, F. F. Holmes, and M. J. McFarlane, "Lung carcinoma in the elderly population. Influence of histology on the inverse relationship of stage to age," Cancer, vol. 60, no. 6, pp. 1331-1336, 1987.

[10] C. H. Geisler, "Autologous transplantation and management of younger patients with mantle cell lymphoma," Best Practice \& Research Clinical Haematology, vol. 25, no. 2, pp. 211-220, 2012.

[11] T. Wasil, S. M. Lichtman, V. Gupta, and S. Rush, "Radiation therapy in cancer patients 80 years of age and older," American Journal of Clinical Oncology, vol. 23, no. 5, pp. 526-530, 2000.

[12] H. Geinitz, F. B. Zimmermann, and M. Molls, "Radiotherapy of the elderly patient. Radiotherapy tolerance and results in older patients," Strahlenther Onkol, vol. 175, pp. 175-119, 1999.

[13] B. Zachariah, L. Balducci, G. V. Venkattaramanabalaji, L. Casey, H. M. Greenberg, and J. A. DelRegato, "Radiotherapy for cancer patients aged 80 and older: A study of effectiveness and side effects," International Journal of Radiation Oncology Biology Physics, vol. 39, no. 5, pp. 1125-1129, 1997.

[14] M. J. Chen and W. Nadalin, "Pecularities of radiation therapy in the elderly," Radiologia Brasileira, vol. 43, pp. 324-329, 2010.

[15] H. Geinitz, F. B. Zimmermann, and M. Molls, "Radiotherapy of the elderly patient. Radiotherapy tolerance and results in older patients," Strahlenther Onkol, vol. 175, pp. 119-127, 1999.

[16] B. S. Gill, B. V. Chapman, K. J. Hansen, P. Sukumvanich, and S. Beriwal, "Primary radiotherapy for nonsurgically managed Stage I endometrial cancer: Utilization and impact of brachytherapy," Brachytherapy, vol. 14, no. 3, pp. 373-379, 2015.

[17] I. H. Kunkler, R. Audisio, Y. Belkacemi et al., "Review of current best practice and priorities for research in radiation oncology for elderly patients with cancer: The international society of geriatric oncology (SIOG) task force," Annals of Oncology, vol. 25, no. 11, 2014.

[18] T.-V. Nguyen and D. G. Petereit, "High-dose-rate brachytherapy for medically inoperable stage I endometrial cancer," Gynecologic Oncology, vol. 71, no. 2, pp. 196-203, 1998.

[19] R. Yancik, "Population aging and cancer: a cross-national concern," Cancer Journal, vol. 11, no. 6, pp. 437-441, 2005.

[20] G. E. Hanks, T. E. Schultheiss, A. Hanlon, and J. B. Owen, "Patterns of radiation treatment of elderly patients with prostate cancer," Cancer, vol. 74, no. 7 S, pp. 2174-2177, 1994.

[21] P. Scalliet, D. Van den Weingaert, and E. Van der Schuren, "Cancer in the Elderly. Treatment and Research," Oxford:oxford medical publications, pp. 28-37, 1994.

[22] L. Bergman, G. Dekker, F. E. van Leeuwen, S. J. Huisman, F. S. A. M. van dam, and J. A. van Dongen, "The effect of age on treatment choice and survival in elderly breast cancer patients," Cancer, vol. 67, no. 9, pp. 2227-2234, 1991.

[23] P. Montemaggi, A. G. Morganti, R. R. Dobelbower Jr. et al., "Role of intraluminal brachytherapy in extrahepatic bile duct and pancreatic cancers: Is it just for palliation?” Radiology, vol. 199, no. 3, pp. 861-866, 1996.

[24] J. R. Diaz-Pavon, F. Cabanillas, A. Majlis, and F. B. Hagemeister, "Outcome of Hodgkin's disease in elderly patients," Hematological Oncology, vol. 13, no. 1, pp. 19-27, 1995.

[25] C. Lemanski, D. Azria, S. Gourgon-Bourgade et al., "Intraoperative radiotherapy in early-stage breast cancer: results of the Montpellier phase II trial," International Journal of Radiation Oncology Biology Physics, vol. 76, no. 3, pp. 698-703, 2010. 
[26] R. E. Wegner, S. Beriwal, D. E. Heron et al., "Definitive radiation therapy for endometrial cancer in medically inoperable elderly patients," Brachytherapy, vol. 9, no. 3, pp. 260-265, 2010.

[27] C. A. M. Marijnen, "External Beam Radiotherapy and High Dose Rate Brachytherapy for Medically Unfit and Elderly Patients," Clinical Oncology, vol. 19, no. 9, pp. 706-710, 2007.

[28] J. P. Gerard, O. Chapet, C. Ortholan, K. Benezery, N. Barbet, and P. Romestaing, "French Experience with Contact X-ray Endocavitary Radiation for Early Rectal Cancer," Clinical Oncology, vol. 19, no. 9, pp. 661-673, 2007.

[29] P. Maingon, S. Guerif, R. Darsouni et al., "Conservative management of rectal adenocarcinoma by radiotherapy," International Journal of Radiation Oncology Biology Physics, vol. 40, no. 5, pp. 1077-1085, 1998.

[30] J.-P. Gerard, A.-C. Frin, J. Doyen et al., "Organ preservation in rectal adenocarcinoma (T1) T2-T3 Nx M0. Historical overview of the Lyon Sud-Nice experience using contact X-ray brachytherapy and external beam radiotherapy for 120 patients," Acta Oncologica, vol. 54, no. 4, pp. 545-551, 2015.

[31] A. Aumock, E. H. Birnbaum, J. W. Fleshman et al., "Treatment of rectal adenocarcinoma with endocavitary and external beam radiotherapy: Results for 199 patients with localized tumors," International Journal of Radiation Oncology Biology Physics, vol. 51, no. 2, pp. 363-370, 2001.

[32] T. Vuong, P. J. Belliveau, R. P. Michel et al., "Conformal preoperative endorectal brachytherapy treatment for locally advanced rectal cancer: Early results of a phase I/II study," Diseases of the Colon \& Rectum, vol. 45, no. 11, pp. 1486-1495, 2002.

[33] T. Vuong, C. Richard, T. Niazi et al., "High dose rate endorectal brachytherapy for patients with curable rectal cancer," Seminars in Colon and Rectal Surgery, vol. 21, no. 2, pp. 115-119, 2010.

[34] P. J. Hoskin, S. M. De Canha, P. Bownes, L. Bryant, and R. G. Jones, "High dose rate afterloading intraluminal brachytherapy for advanced inoperable rectal carcinoma," Radiotherapy \& Oncology, vol. 73, no. 2, pp. 195-198, 2004.

[35] C. Corner, L. Bryant, C. Chapman, R. Glynne-Jones, and P. J. Hoskin, "High-dose-rate afterloading intraluminal brachytherapy for advanced inoperable rectal carcinoma," Brachytherapy, vol. 9, no. 1, pp. 66-70, 2010.

[36] J. Papillon and J. F. Montbarbon, "Epidermoid carcinoma of the anal canal - A series of 276 cases," Diseases of the Colon \& Rectum, vol. 30, no. 5, pp. 324-333, 1987.

[37] F. M. Smith, A. Al-Amin, A. Wright, J. Berry, J. J. Nicoll, and A. Sun Myint, "Contact radiotherapy boost in association with 'watch and wait' for rectal cancer: initial experience and outcomes from a shared programme between a district general hospital network and a regional oncology centre," Colorectal Disease, vol. 18, no. 9, pp. 861-870, 2016.

[38] A. L. Appelt and D. Sebag-Montefiore, "Technological advances in radiotherapy of rectal cancer: Opportunities and challenges," Current Opinion in Oncology, vol. 28, no. 4, pp. 353-358, 2016.

[39] B. Engels, K. Tournel, H. Everaert et al., "Phase II study of preoperative helical tomotherapy with a simultaneous integrated boost for rectal cancer," International Journal of Radiation Oncology Biology Physics, vol. 83, no. 1, pp. 142-148, 2012.

[40] J. Skowronek and G. Zwierzchowski, "Brachytherapy in the treatment of bile duct cancer - A tough challenge," Journal of Contemporary Brachytherapy, vol. 9, no. 2, pp. 187-195, 2017.

[41] J. Karani, M. Fletcher, D. Brinkley, J. L. Dawson, R. Williams, and H. Nunnerley, "Internal biliary drainage and local radiotherapy with iridium-192 wire in treatment of hilar cholangiocarcinoma," Clinical Radiology, vol. 36, no. 6, pp. 603-606, 1985.
[42] V. Válek, P. Kysela, Z. Kala, I. Kiss, J. Tomášek, and J. Petera, "Brachytherapy and percutaneous stenting in the treatment of cholangiocarcinoma: A prospective randomised study," European Journal of Radiology, vol. 62, no. 2, pp. 175-179, 2007.

[43] G. C. Mattiucci, R. Autorino, A. Tringali et al., "A Phase I study of high-dose-rate intraluminal brachytherapy as palliative treatment in extrahepatic biliary tract cancer," Brachytherapy, vol. 14, no. 3, pp. 401-404, 2015.

[44] M. Morris, P. J. Eifel, J. Lu et al., "Pelvic radiation with concurrent chemotherapy compared with pelvic and para-aortic radiation for high-risk cervical cancer," The New England Journal of Medicine, vol. 340, no. 15, pp. 1137-1143, 1999.

[45] H. M. Keys, J. A. Roberts, V. L. Brunetto et al., "A phase III trial of surgery with or without adjunctive external pelvic radiation therapy in intermediate risk endometrial adenocarcinoma: a Gynecologic Oncology Group study," Gynecologic Oncology, vol. 92, no. 3, pp. 744-751, 2004.

[46] J. S. Goodwin, J. M. Samet, and W. C. Hunt, "Determinants of Survival in Older Cancer Patients," JNCI Journal of the National Cancer Institute, vol. 88, no. 15, pp. 1031-1038, 1996.

[47] J. Samet, W. C. Hunt, C. Key, C. G. Humble, and J. S. Goodwin, "Choice of Cancer Therapy Varies With Age of Patient," Journal of the American Medical Association, vol. 255, no. 24, pp. 33853390,1986

[48] M. A. Schonberg, E. R. Marcantonio, D. Li, R. A. Silliman, L. Ngo, and E. P. McCarthy, "Breast cancer among the oldest old: tumor characteristics, treatment choices, and survival," Journal of Clinical Oncology, vol. 28, no. 12, pp. 2038-2045, 2010.

[49] S. Cykert, P. Dilworth-Anderson, M. H. Monroe et al., "Factors associated with decisions to undergo surgery among patients with newly diagnosed early-stage lung cancer," Journal of the American Medical Association, vol. 303, no. 23, pp. 2368-2376, 2010.

[50] M. Rotman, A. Sedlis, M. R. Piedmonte et al., "A phase III randomized trial of postoperative pelvic irradiation in Stage IB cervical carcinoma with poor prognostic features: follow-up of a gynecologic oncology group study," International Journal of Radiation Oncology Biology Physics, vol. 65, no. 1, pp. 169-176, 2006.

[51] M. Y. Lin, S. Kondalsamy-Chennakesavan, D. Bernshaw, P. Khaw, and K. Narayan, "Carcinoma of the cervix in elderly patients treated with radiotherapy: Patterns of care and treatment outcomes," Journal of Gynecologic Oncology, vol. 27, no. 6, article no. e59, 2016.

[52] S.-W. Chen, J.-A. Liang, S.-N. Yang, and F.-J. Lin, "High doserate brachytherapy for elderly patients with uterine cervical cancer," Japanese Journal of Clinical Oncology, vol. 33, no. 5, pp. 221-228, 2003.

[53] Y. Yanazume, S. Yanazume, K. Iio et al., "Major causes of impractical brachytherapy in elderly patients with uterine cervical cancer," Journal of Obstetrics and Gynaecology Research, vol. 40, no. 6, pp. 1725-1732, 2014.

[54] N. D. Fleming, S. E. Lentz, I. Cass, A. J. Li, B. Y. Karlan, and C. $\mathrm{S}$. Walsh, "Is older age a poor prognostic factor in stage $\mathrm{i}$ and II endometrioid endometrial adenocarcinoma?" Gynecologic Oncology, vol. 120, no. 2, pp. 189-192, 2011.

[55] J. A. Lachance, E. N. Everett, B. Greer et al., "The effect of age on clinical/pathologic features, surgical morbidity, and outcome in patients with endometrial cancer," Gynecologic Oncology, vol. 101, no. 3, pp. 470-475, 2006. 
[56] G. Siesto, S. Uccella, F. Ghezzi et al., "Surgical and survival outcomes in older women with endometrial cancer treated by laparoscopy," Menopause, vol. 17, no. 3, pp. 539-544, 2010.

[57] L. Dumas, A. Ring, J. Butler, T. Kalsi, D. Harari, and S. Banerjee, "Improving outcomes for older women with gynaecological malignancies," Cancer Treatment Reviews, vol. 50, pp. 99-108, 2016.

[58] K. M. Alektiar, E. Venkatraman, N. Abu-Rustum, and R. R. Barakat, "Is Endometrial Carcinoma Intrinsically More Aggressive in Elderly Patients?" Cancer, vol. 98, no. 11, pp. 2368-2377, 2003.

[59] P. De Marzi, J. Ottolina, G. Mangili et al., "Surgical treatment of elderly patients with endometrial cancer ( $\geq 65$ years)," Journal of Geriatric Oncology, vol. 4, no. 4, pp. 368-373, 2013.

[60] S. Jolly, C. E. Vargas, T. Kumar et al., "The impact of age on longterm outcome in patients with endometrial cancer treated with postoperative radiation," Gynecologic Oncology, vol. 103, no. 1, pp. 87-93, 2006.

[61] J. Alejandro Rauh-Hain, K. J. Pepin, L. A. Meyer et al., "Management for elderly women with advanced-stage, high-grade endometrial cancer," Obstetrics \& Gynecology, vol. 126, no. 6, pp. 1198-1206, 2015.

[62] J. D. Wright, S. N. Lewin, N. I. Barrena Medel et al., "Endometrial cancer in the oldest old: Tumor characteristics, patterns of care, and outcome," Gynecologic Oncology, vol. 122, no. 1, pp. 6974, 2011.

[63] S. Uccella, M. Bonzini, S. Palomba et al., "Laparoscopic vs. open treatment of endometrial cancer in the elderly and very elderly: An age-stratified multicenter study on 1606 women," Gynecologic Oncology, vol. 141, no. 2, pp. 211-217, 2016.

[64] H. Eggemann, T. Ignatov, E. Burger, S. D. Costa, and A. Ignatov, "Management of elderly women with endometrial cancer," Gynecologic Oncology, vol. 146, no. 3, pp. 519-524, 2017.

[65] T. Susini, G. Massi, G. Amunni et al., "Vaginal hysterectomy and abdominal hysterectomy for treatment of endometrial cancer in the elderly," Gynecologic Oncology, vol. 96, no. 2, pp. 362-367, 2005.

[66] Z. Vaknin, I. Ben-Ami, D. Schneider, M. Pansky, and R. Halperin, "A comparison of perioperative morbidity, perioperative mortality, and disease-specific survival in elderly women ( $\geq 70$ years) versus younger women ( $<70$ years) with endometrioid endometrial cancer," International Journal of Gynecological Cancer, vol. 19, no. 5, pp. 879-883, 2009.

[67] D. R. Scribner Jr., J. L. Walker, G. A. Johnson, S. D. McMeekin, M. A. Gold, and R. S. Mannel, "Surgical management of earlystage endometrial cancer in the elderly: is laparoscopy feasible?" Gynecologic Oncology, vol. 83, no. 3, pp. 563-568, 2001.

[68] V. Lavoue, X. Zeng, S. Lau et al., "Impact of robotics on the outcome of elderly patients with endometrial cancer," Gynecologic Oncology, vol. 133, no. 3, pp. 556-562, 2014.

[69] P. T. Truong, H. A. Kader, B. Lacy et al., "The effects of age and comorbidity on treatment and outcomes in women with endometrial cancer," American Journal of Clinical Oncology, vol. 28, no. 2, pp. 157-164, 2005.

[70] S. W. Dutta, D. M. Trifiletti, S. Grover, P. Boimel, and T. N. Showalter, "Management of elderly patients with early-stage medically inoperable endometrial cancer: Systematic review and National Cancer Database analysis," Brachytherapy, vol. 16, no. 3, pp. 526-533, 2017.

[71] H. Kucera, T. H. Knocke, E. Kucera, and R. Potter, “Treatment of endometrial carcinoma with high-dose-rate brachytherapy alone in medically inoperable stage I patients," Acta Obstetricia et Gynecologica Scandinavica, vol. 77, no. 10, pp. 1008-1012, 1998.

[72] T. Tarver, "Cancer Facts \& Figures 2012. American Cancer Society (ACS)," Journal of Consumer Health On the Internet, vol. 16, no. 3, pp. 366-367, 2012.

[73] F. Fiorica, G. Zini, F. Cartei, M. V. Candela et al., "Radiotherapy and comorbidity assessment in older and oldest elderly endometrial cancer patients: a retrospective analysis," World Cancer Research Journal, vol. 1, no. 1, p. e55, 2014.

[74] S. Kellas-Śleczka, B. Białas, M. Fijałkowski et al., "Interstitial high-dose-rate brachytherapy in locally advanced and recurrent vulvar cancer," Journal of Contemporary Brachytherapy, vol. 8, no. 1, pp. 32-40, 2016.

[75] C. Charra, P. Roy, R. Coquard, P. Romestaing, J. M. Ardiet, and J. P. Gérard, "Outcome of treatment of upper third vaginal recurrences of cervical and endometrial carcinomas with interstitial brachytherapy," International Journal of Radiation Oncology Biology Physics, vol. 40, no. 2, pp. 421-426, 1998.

[76] R. Makarewicz, "The place of interstitial treatment in the management of vulvar carcinoma," Reports of Practical Oncology, vol. 1, no. 2, pp. 86-88, 1996.

[77] A. Hasbini, C. Haie-Meder, P. Morice et al., "Outcome after salvage radiotherapy (brachytherapy $+/$ - external) in patients with a vaginal recurrence from endometrial carcinomas," Radiotherapy \& Oncology, vol. 65, no. 1, pp. 23-28, 2002.

[78] A. Katz, PJ. Eifel, A. Jhingran, and C. F. Levenback, “The role of radiation therapy in preventing regional recurrences of invasive squamous cell carcinoma of the vulva," International Journal of Radiation Oncology Biology Physics, vol. 57, pp. 409-418, 2003.

[79] S. Nag, S. Yacoub, L. J. Copeland, and J. M. Fowler, "Interstitial brachytherapy for salvage treatment of vaginal recurrences in previously unirradiated endometrial cancer patients," International Journal of Radiation Oncology Biology Physics, vol. 54, no. 4, pp. 1153-1159, 2002.

[80] A. R. Seeger, A. Windschall, M. Lotter et al., "The role of interstitial brachytherapy in the treatment of vaginal and vulvar malignancies," Strahlentherapie und Onkologie, vol. 182, no. 3, pp. 142-148, 2006.

[81] U. Mahantshetty, P. Naga, R. Engineer et al., "Clinical outcome of high-dose-rate interstitial brachytherapy in vulvar cancer: A single institutional experience," Brachytherapy, vol. 16, no. 1, pp. 153-160, 2017.

[82] K. S. Tewari, F. Cappuccini, A. A. Puthawala et al., "Primary invasive carcinoma of the vagina: Treatment with interstitial brachytherapy," Cancer, vol. 91, no. 4, pp. 758-770, 2001.

[83] S. Pohar, S. Hoffstetter, D. Peiffert, E. Luporsi, and M. Pernot, "Primary invasive carcinoma of the vagina," Cancer, vol. 91, pp. 758-770, 2001.

[84] American cancer Society: Cancer Facts and Figures, American Cancer Society, Atlanta/USA, 2017, https://www.cancer.org/ research/cancer-facts-statistics/all-cancer-facts-figures/cancerfacts-figures-2017.html.

[85] K. Yoshida, H. Yamazaki, S. Nakamura et al., "Comparisons of late vaginal mucosal reactions between interstitial and conventional intracavitary brachytherapy in patients with gynecological cancer: Speculation on the relation between pallor reaction and stenosis," Anticancer Reseach, vol. 33, no. 9, pp. 3963-3968, 2013.

[86] G. Kovács, "Modern head and neck brachytherapy: From radium towards intensity modulated interventional brachytherapy," Journal of Contemporary Brachytherapy, vol. 6, no. 4, pp. 404416, 2014. 
[87] C. P. Schofield, A. J. Sykes, N. J. Slevin, and N. Z. Z. Rashid, "Radiotherapy for head and neck cancer in elderly patients," Radiotherapy \& Oncology, vol. 69, no. 1, pp. 37-42, 2003.

[88] M. Kos, K. Luczak, J. Godzinski, and J. Klempous, "Treatment of monostotic fibrous dysplasia with pamidronate," Journal of Cranio-Maxillo-Facial Surgery, vol. 32, no. 1, pp. 10-15, 2004.

[89] G. Kovács, R. Martinez-Monge, A. Budrukkar et al., "GECESTRO ACROP recommendations for head \& neck brachytherapy in squamous cell carcinomas: 1st update - Improvement by cross sectional imaging based treatment planning and stepping source technology," Radiotherapy \& Oncology, vol. 122, no. 2, pp. 248-254, 2017.

[90] M. Gaztanaga, I. San Miguel, M. E. Rodriquez et al., "289 oral limited-volume perioperative hdr brachytherapy as a substitute for wide-field ebrt in resected head \& neck cancer," Radiotherapy and Oncology, 2011.

[91] K. Yuasa-Nakagawa, R. Yoshimura, H. Watanabe et al., "Brachytherapy for the very elderly with oral and oropharyngeal cancers," Annals of Oncology, vol. 26, pp. 93-102, 2015.

[92] H. Yamazaki, K. Yoshida, T. Kotsuma et al., "Age is not a limiting factor for brachytherapy for carcinoma of the node negative oral tongue in patients aged eighty or older," Journal of Radiation Oncology, vol. 5, no. 1, article no. 116, 2010.

[93] R. Khalilur, K. Hayashi, and H. Shibuya, "Brachytherapy for tongue cancer in the very elderly is an alternative to external beam radiation," British Journal of Radiology, vol. 84, no. 1004, pp. 747-749, 2011.

[94] J.-L. Guinot, L. Arribas, J. B. Vendrell et al., "Prognostic factors in squamous cell lip carcinoma treated with high-dose-rate brachytherapy," Head \& Neck, vol. 36, no. 12, pp. 1737-1742, 2014.

[95] Y. Zhang, J.-L. Yi, X.-D. Huang et al., "Inherently poor survival of elderly patients with nasopharyngeal carcinoma," Head \& Neck, vol. 37, no. 6, pp. 771-776, 2015.

[96] H. Zeng, R. Zheng, S. Zhang et al., "Esophageal cancer statistics in China, 2011: Estimates based on 177 cancer registries," Thoracic Cancer, vol. 7, no. 2, pp. 232-237, 2016.

[97] W. Chen, R. Zheng, P. D. Baade et al., "Cancer statistics in China, 2015," CA: A Cancer Journal for Clinicians, vol. 66, no. 2, pp. 115$132,2016$.

[98] J. S. Cooper, M. D. Guo, A. Herskovic et al., "Chemoradiotherapy of locally advanced esophageal cancer: Long-term followup of a prospective randomized trial (RTOG 85-01)," Journal of the American Medical Association, vol. 281, no. 17, pp. 1623-1627, 1999.

[99] T. Li, W. Zhang, J. Lv et al., "Safety and outcome of external beam radiation and neutron brachytherapy in elderly patients with esophageal squamous cell cancer," Journal of Contemporary Brachytherapy, vol. 9, no. 1, pp. 36-43, 2017.

[100] C. D. Amdal, A.-B. Jacobsen, B. Sandstad, T. Warloe, and K. Bjordal, "Palliative brachytherapy with or without primary stent placement in patients with oesophageal cancer, a randomised phase III trial," Radiotherapy \& Oncology, vol. 107, no. 3, pp. 428433, 2013

[101] I. Mallick, S. C. Sharma, and D. Behera, "Endobronchial brachytherapy for symptom palliation in non-small cell lung cancer-Analysis of symptom response, endoscopic improvement and quality of life," Lung Cancer, vol. 55, no. 3, pp. 313-318, 2007.

[102] R. J. McKenna, A. Mahtabifard, J. Yap et al., "Wedge Resection and Brachytherapy for Lung Cancer in Patients With Poor Pulmonary Function," The Annals of Thoracic Surgery, vol. 85, no. 2, pp. S733-S736, 2008.
[103] R. Santos, A. Colonias, D. Parda et al., "Comparison between sublobar resection and 125Iodine brachytherapy after sublobar resection in high-risk patients with Stage I non-small-cell lung cancer," Surgery, vol. 134, no. 4, pp. 691-697, 2003.

[104] J. Song, X. Fan, Z. Zhao et al., "125I brachytherapy of locally advanced non-small-cell lung cancer after one cycle of firstline chemotherapy: A comparison with best supportive care," OncoTargets and Therapy, vol. 10, pp. 1345-1352, 2017.

[105] A. F. Cardona, L. Reveiz, E. G. Ospina et al., "Medical Policy Endobronchial Brachytherapy," Cochrane Database of Systematic Reviews, no. 2, Article ID CD004284, 2008.

[106] Y. C. Ung, E. Yu, C. Falkson et al., "The role of high-dose-rate brachytherapy in the palliation of symptoms in patients with non-small-cell lung cancer: A systematic review," Brachyther$a p y$, vol. 5, no. 3, pp. 189-202, 2006.

[107] V. K. Sangar, N. Ragavan, S. S. Matanhelia, M. W. Watson, and R. A. Blades, "The economic consequences of prostate and bladder cancer in the UK," BJU International, vol. 95, no. 1, pp. 59-63, 2005.

[108] T. A. Stamey, "The era of serum prostate specific antigen as a marker for biopsy of the prostate and detecting prostate cancer is now over in the USA," BJU International, vol. 94, no. 7, pp. 963-964, 2004.

[109] P. J. Hoskin, P. J. Bownes, P. Ostler, K. Walker, and L. Bryant, "High dose rate afterloading brachytherapy for prostate cancer: Catheter and gland movement between fractions," Radiotherapy \& Oncology, vol. 68, no. 3, pp. 285-288, 2003.

[110] F. A. Vicini, A. Martinez, G. Hanks et al., "An interinstitutional and interspecialty comparison of treatment outcome data for patients with prostate carcinoma based on predefined prognostic categories and minimum follow-up," Cancer, vol. 95, no. 10, pp. 2126-2135, 2002.

[111] M. R. Cooperberg, D. P. Lubeck, M. V. Meng, S. S. Mehta, and P. R. Carroll, "The changing face of low-risk prostate cancer: Trends in clinical presentation and primary management," Journal of Clinical Oncology, vol. 22, no. 11, pp. 2141-2149, 2004.

[112] Y.-N. Wong, N. Mitra, G. Hudes et al., "Survival associated with treatment vs observation of localized prostate cancer in elderly men," The Journal of the American Medical Association, vol. 296, no. 22, pp. 2683-2693, 2006.

[113] Y. Yamada, S. Bhatia, M. Zaider et al., "Favorable clinical outcomes of three-dimensional computer-optimized high-doserate prostate brachytherapy in the management of localized prostate cancer," Brachytherapy, vol. 5, no. 3, pp. 157-164, 2006.

[114] N. Zamboglou, N. Tselis, D. Baltas et al., "High-dose-rate interstitial brachytherapy as monotherapy for clinically localized prostate cancer: Treatment evolution and mature results," International Journal of Radiation Oncology • Biology $\bullet$ Physics, vol. 85, no. 3, pp. 672-678, 2013.

[115] A. L. Liss, E. I. Abu-Isa, M. S. Jawad et al., "Combination therapy improves prostate cancer survival for patients with potentially lethal prostate cancer: The impact of Gleason pattern 5," Brachytherapy, vol. 14, no. 4, pp. 502-510, 2015.

[116] K. E. Hoffman, M.-H. Chen, B. J. Moran et al., "Prostate cancerspecific mortality and the extent of therapy in healthy elderly men with high-risk prostate cancer," Cancer, vol. 116, no. 11, pp. 2590-2595, 2010.

[117] J. Skowronek, "Brachytherapy in the therapy of prostate cancer - An interesting choice," Wspolczesna Onkologia, vol. 17, no. 5, pp. 407-412, 2013. 
[118] I. Henríquez, G. Sancho, A. Hervás et al., "Salvage brachytherapy in prostate local recurrence after radiation therapy: Predicting factors for control and toxicity," Journal of Radiation Oncology, vol. 9, no. 1, article no. 102, 2014.

[119] P. Niehoff, T. Loch, N. Nürnberg et al., "Feasibility and preliminary outcome of salvage combined HDR brachytherapy and external beam radiotherapy (EBRT) for local recurrences after radical prostatectomy," Brachytherapy, vol. 4, no. 2, pp. 141-145, 2005.

[120] M. A. Bernier, F. R. Ruiz, M. De Troya Martín, and N. B. Sánchez, "Comparative epidemiological study of non-melanoma skin cancer between Spanish and north and central European residents on the Costa del Sol," Journal of the European Academy of Dermatology and Venereology, vol. 26, no. 1, pp. 4147, 2012.

[121] Wu. TP and JA. Stein, "Non-melanoma skin cancer in young women," Journal of Drugs in Dermatology, vol. 12, pp. 568-572, 2013.

[122] C. M. Clark, M. Furniss, and J. M. Mackay-Wiggan, "Basal cell carcinoma: An evidence-based treatment update," American Journal of Clinical Dermatology, vol. 15, no. 3, pp. 197-216, 2014.

[123] F. J. Bath-Hextall, W. Perkins, J. Bong, and H. C. Williams, "Interventions for basal cell carcinoma of the skin," Cochrane Database of Systematic Reviews, no. 1, Article ID CD003412, 2007.

[124] R. Ballester-Sánchez, O. Pons-Llanas, C. Candela-Juan et al., "Efficacy and safety of electronic brachytherapy for superficial and nodular basal cell carcinoma," Journal of Contemporary Brachytherapy, vol. 7, no. 3, pp. 231-238, 2015.

[125] R. Jumeau, S. Renard-Oldrini, F. Courrech et al., "High dose rate brachytherapy with customized applicators for malignant facial skin lesions," Cancer Radiothérapie, vol. 20, no. 5, pp. 341-346, 2016.

[126] G. G. Kimmick and L. Balducci, "Breast cancer and aging: Clinical interactions," Hematology/Oncology Clinics of North America, vol. 14, no. 1, pp. 213-234, 2000.

[127] R. Yancik, "Cancer burden in the aged: An epidemiologic and demographic overview," Cancer, vol. 80, no. 7, pp. 1273-1283, 1997.

[128] L. Talarico, G. Chen, and R. Pazdur, "Enrollment of elderly patients in clinical trials for cancer drug registration: A 7-year experience by the US Food and Drug Administration," Journal of Clinical Oncology, vol. 22, no. 22, pp. 4626-4631, 2004.

[129] N. Hébert-Croteau, J. Brisson, J. Latreille, C. Blanchette, and L. Deschênes, "Compliance with consensus recommendations for the treatment of early stage breast carcinoma in elderly women," Cancer, vol. 85, no. 5, pp. 1104-1113, 1999.

[130] C. Bouchardy, E. Rapiti, G. Fioretta et al., "Undertreatment strongly decreases prognosis of breast cancer in elderly women," Journal of Clinical Oncology, vol. 21, no. 19, pp. 3580-3587, 2003.

[131] R. A. Silliman, S. L. Troyan, E. Guadagnoli, S. H. Kaplan, and S. Greenfield, "The impact of age, marital status, and physicianpatient interactions on the care of older women with breast carcinoma," Cancer, vol. 80, no. 7, pp. 1326-1334, 1997.

[132] K. S. Hughes, L. A. Schnaper, J. R. Bellon et al., "Lumpectomy plus tamoxifen with or without irradiation in women age 70 years or older with early breast cancer: long-term follow-up of CALGB 9343," Journal of Clinical Oncology, vol. 31, no. 19, pp. 2382-2387, 2013.

[133] I. H. Kunkler, L. J. Williams, W. J. L. Jack, D. A. Cameron, and J. M. Dixon, "Breast-conserving surgery with or without irradiation in women aged 65 years or older with early breast cancer (PRIME II): A randomised controlled trial," The Lancet Oncology, vol. 16, no. 3, pp. 266-273, 2015.

[134] S. Sumodhee, J. Levy, E. Chamorey et al., "Accelerated partial breast irradiation for elderly women with early breast cancer: A compromise between whole breast irradiation and omission of radiotherapy," Brachytherapy, vol. 16, no. 5, pp. 929-934, 2017.

[135] C. Genebes, M.-E. Chand, J. Gal et al., "Accelerated partial breast irradiation in the elderly: 5-year results of high-dose rate multicatheter brachytherapy," Journal of Radiation Oncology, vol. 9, no. 1, article no. 115, 2014.

[136] V. Valentini, F. Miccichè, L. Tagliaferri et al., "Spider-H\&N: Managing clinical data of head\&neck cancer patients treated through a multidisciplinary approach," Radiotherapy \& Oncology, vol. 82, pp. S76-S77, 2007.

[137] L. Tagliaferri, G. Kovács, R. Autorino et al., "ENT COBRA (Consortium for Brachytherapy Data Analysis): Interdisciplinary standardized data collection system for head and neck patients treated with interventional radiotherapy (brachytherapy)," Journal of Contemporary Brachytherapy, vol. 8, no. 4, pp. 336-343, 2016. 


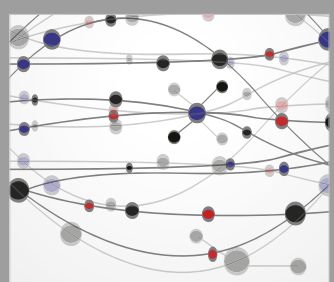

The Scientific World Journal
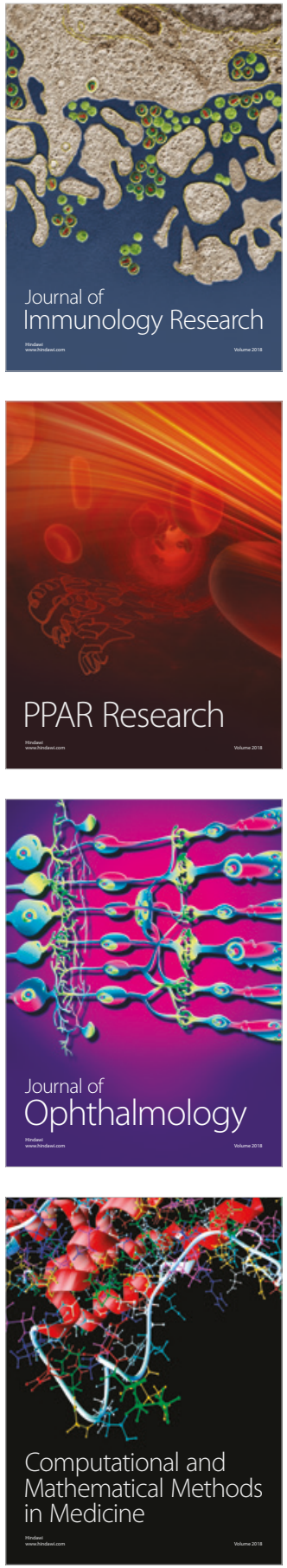

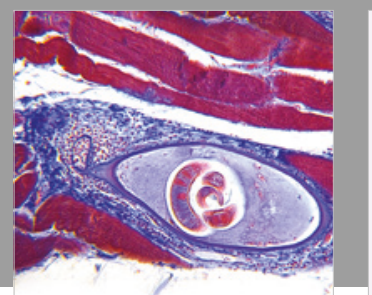

Gastroenterology Research and Practice

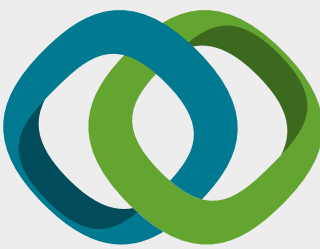

\section{Hindawi}

Submit your manuscripts at

www.hindawi.com
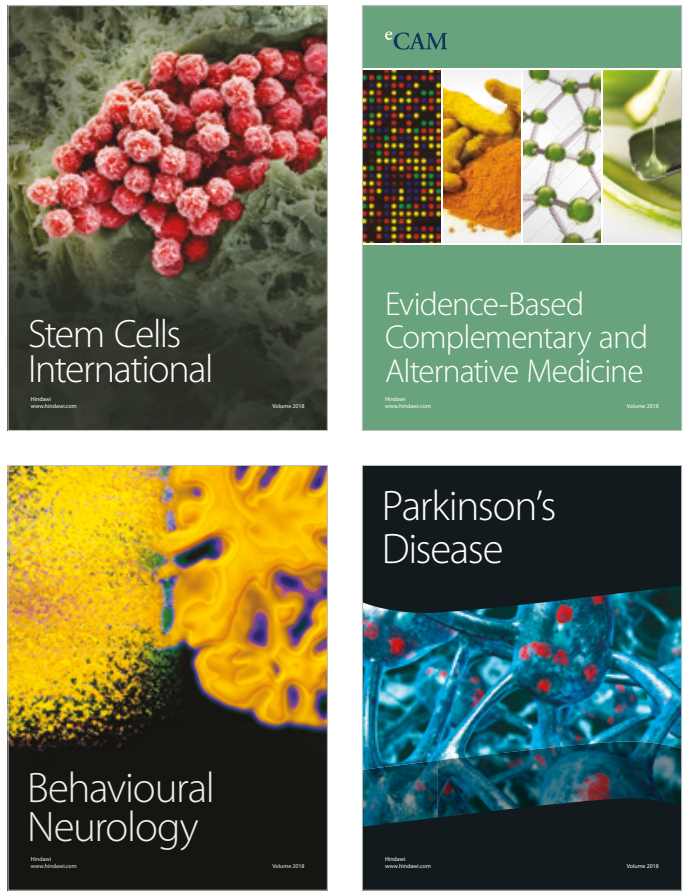

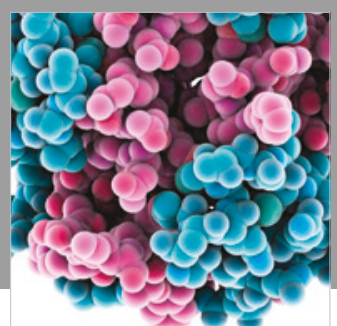

ournal of

Diabetes Research

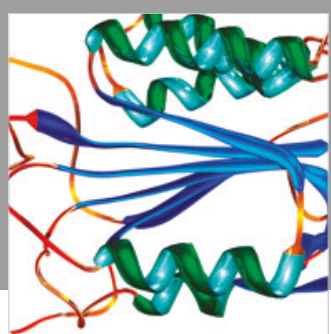

Disease Markers
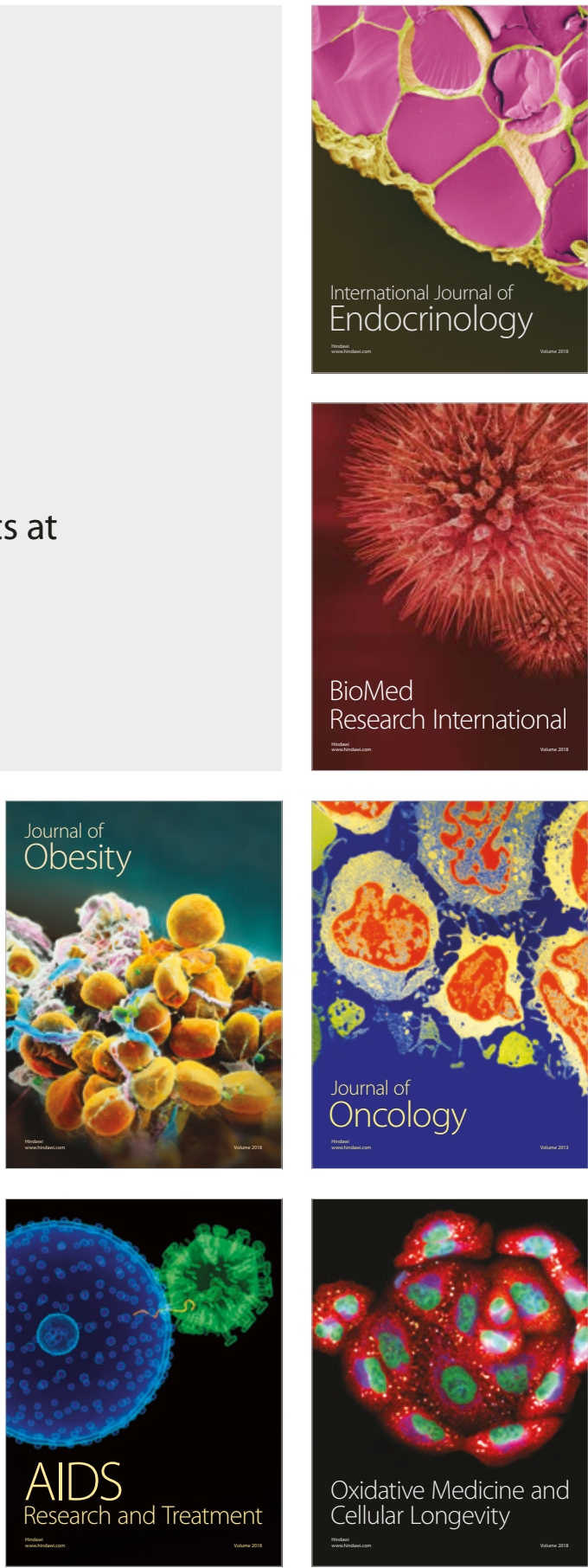